\title{
Assemblages of sessile marine invertebrates: still changing after all these years?
}

\author{
A. J. Butler ${ }^{1, *}$, R. M. Connolly ${ }^{2}$ \\ ${ }^{1}$ Department of Zoology, University of Adelaide, South Australia 5005, Australia \\ ${ }^{2}$ School of Environmental and Applied Science, Griffith University, Gold Coast, Queensland 9726, Australia
}

\begin{abstract}
The fouling organisms on Port Bonython pier, South Australia, had previously been monitored for 6.5 yr after initial immersion of piles using photographs of fixed positions and direct observation by divers. Up to that date it appeared that predictions based on experiments at more sheltered sites had not been fulfilled. In particular, the assemblage had not become dominated by modular organisms. The rate of change seemed to be slowing after $6.5 \mathrm{yr}$ but this could not be tested. The assemblage on the piles was re-examined in December 1995, after a further 7 yr. Faunal composition differed at sites along the pier throughout the study, and still did so after $13.5 \mathrm{yr}$, but the composition at all sites tended to change in a similar way through time; positions differed in a consistent way at 6.5 and 13.5 yr, probably reflecting consistent environmental differences between sites along the pier. Abundances of key taxa fluctuated markedly from site to site at any one time, and through time. As originally predicted, after $13.5 \mathrm{yr}$ much of the pile surface area had become covered by encrusting or mound-forming modular animals (54\%), especially sponges, and by foliose red algae $(25 \%)$; unitary organisms such as bivalves and solitary ascidians had become greatly reduced in abundance. It is now clear that the overall composition of the assemblage had not converged to a 'stable' condition by $6.5 y$; more sampling dates would be needed to determine whether it had done so by 13.5 yr.
\end{abstract}

KEY WORDS: Assemblage - Dynamics - Fouling fauna - Modular organisms - Ascidians - Sponges · Octocorals - Bivalves

\section{INTRODUCTION}

In early 1982, Santos Ltd began construction of the hydrocarbon-loading facility to be called Port Bonython, at Stony Point in Spencer Gulf, South Australia. The monitoring of sessile organisms attached to the piles gave an opportunity to test hypotheses about recruitment and dynamics of subtidal assemblages of sessile invertebrates. The model, developed from experiments on piers in more sheltered waters in an adjacent gulf (Kay \& Keough 1981, Kay \& Butler 1983, Keough 1984a, Butler 1986, 1991, Butler \& Chesson 1990), emphasised the importance of the long life and vegetative growth of modular organisms in maintaining the composition of the assemblage and a signifi-

\footnotetext{
- Present address: CSIRO Marine Research, GPO Box 1538 , Hobart, Tasmania 7001, Australia.

E-mail: alan.butler@marine.csiro.au
}

cant contribution from locally produced, short-lived pelagic larvae (Keough \& Chernoff 1987, Davis \& Butler 1989) so that reproduction in the assemblage was mainly local. Such systems do not appear to be dominated by species with teleplanic larvae (Butler \& Keough 1990). This led us to expect that in the assemblage at Port Bonython, although initial colonists would be strongly influenced by the fecundity and dispersive ability of the organisms occupying neighbouring natural hard substrata, the fauna on different groups of piles would converge to some common composition dominated by modular organisms, and that the assemblage would converge to a 'stable' condition (showing little change with time; cf. Kay \& Butler 1983, Keough \& Butler 1983).

This model is in general accordance with the findings of studies elsewhere (e.g. Sebens 1985). There have been many studies of ecological processes in such communities (competition for space and food-Jack- 
son 1977, 1979, Buss 1979, Buss \& Jackson 1979, Kay \& Keough 1981, Okamura 1988, McKinney 1992; predation - Russ 1980, Osman et al. 1992; substratum sizeConnell \& Keough 1985, Butler 1991; and interactions amongst such factors-Keough 1984b, Sebens 1985 , Chernoff 1987, Butler \& Chesson 1990, Coyer et al. 1993), of their recruitment, initial development and short-term dynamics (Osman 1977. Anger 1978, Sutherland 1981, Schmidt \& Warner 1984, Olson 1985, Davis 1987, 1988, Osman et al. 1989, 1992), some observations of the longer-term dynamics of established assemblages (Svane \& Lundalv 1981, Christie 1983), and certainly much written about relevant theory (Sutherland 1974, 1981, Karlson \& Jackson 1981, Karlson \& Buss 1984, Karlson 1985, Butler \& Chesson 1990). There have, however, been few opportunities both to observe the establishment of a fouling assemblage on large hard substrata and to follow its development over a long period. Thus, there is a gap in our understanding of such systems - we know much about establishment and early development processes and much about the dynamics of established communities, but little about the longer-term development of the assemblage leading to a state we may call 'established'. This development may take a Ionger timeperiod than hitherto believed.

In the case of Port Bonython, Butler \& Connolly (1996) reported the results of monitoring the fouling fauna for ca $6.5 \mathrm{yr}$ after initial immersion of piles. Faunal composition differed at sites along the pier throughout the study, but the composition at all sites tended to change in a similar way over time, and seemed to be changing more slowly near the end of the study. Abundances of key taxa fluctuated markedly from site to site along the pier. Solitary organisms such as bivalves and solitary ascidians, which were expected to be overgrown, persisted in great abundance throughout the study, although over $50 \%$ of pile surface area was covered by encrusting or moundforming colonial animals such as sponges and colonial ascidians. Significant differences amongst sites after ca $6.5 \mathrm{yr}$, both in assemblages and in abundances of key taxa, did not match available data on environmental variables (degree of shading, depth of seabed, disturbance due to wave action, release of treated ballast water), although there were signs of an effect of high current speeds associated with a local gyre.

Butler \& Connolly (1996) concluded that their observations could be explained in a range of ways which could be distilled into 2 models. Model 1 was that there was patchiness or 'noise', and continual variation in the system on a large scale (between positions along the pier), as well as on smaller scales, but no major environmental pattern. Overall, the assemblage may have been tracking towards the narrowly stochasti- cally bounded' situation characteristic of several sites in Gulf St Vincent (Kay \& Butler 1983), but had not displayed this over its first 6 to $7 \mathrm{yr}$. We identify 2 variants of this model. Model 1A says that the system had converged to the condition of 'narrow stochastic boundedness' by $6.5 \mathrm{yr}$, and Model $1 \mathrm{~B}$ says that the convergence had not yet occurred by 6.5 yr.

Model 2 is that the position differences were not merely 'noise' but reflected environmental differences between positions, such as differences in current speed. Again we must consider 2 variants: Model $2 \mathrm{~A}$ that each position had converged to the condition of 'narrow stochastic boundedness' (but this time with persistent differences between positions) by $6.5 \mathrm{yr}$, and Model 2B that the convergence had not yet occurred by 6.5 yr.

An appropriate test would be to resurvey the pier after a further 6 to $8 \mathrm{yr}$, when these models give rise to different predictions. They are as follows. Model $1 \mathrm{~A}$ predicts that positions would differ from one another and each position would differ from its condition in 1989 , but that the pier as a whole would not be strongly different from 1989; a 2-way analysis of similarities (ANOSIM) (factors Date with 2 levels and Position with 5 levels) should find significant position effects overall, little overall date effect but a significant interaction between date and position, evidenced by different position effects at each date. Model $1 \mathrm{~B}$ predicts that positions would differ from one another, each position would differ from its condition in 1989, and the overall composition of the pier would differ from that in 1989; a 2-way ANOSIM should find significant position effects, a date effect and an interaction. Model 2A predicts that on a future visit we would find not only that the composition of the assemblage over the whole pier is similar to that in 1989 (after $6.5 \mathrm{yr}$ ) but also that each position is similar to its composition then, and that positions differ in the same ways; a 2-way ANOSIM (date-position) should find a significant position effect but no significant date effect nor implied interaction. Finally Model 2B predicts that the pier as a whole would have continued to change, that positions would continue to differ from one another but, since this model postulates a continuing succession at each position but that the positions have different environments, it is not possible to predict whether they would appear to move 'in parallel' in multivariate space; thus, there would be a significant date effect, a significant position effect, but we cannot predict whether there would be a significant implied interaction between date and position.

In December 1995, after a further $7 \mathrm{yr}$, we revisited the site and repeated the earlier surveys to distinguish between these possibilities; the results are reported here. 


\section{METHODS}

The study site (Port Bonython; 33 $1^{\prime} \mathrm{S}, 137^{\circ} 46^{\prime} \mathrm{E}$ ) and pier are described in Butler \& Connolly (1996). Observations were made on 2 piles at each of 4 groups or 'bents' of piles spaced along the trestle and 2 piles at the loading platform; these are labelled positions 1 to 5 .

Photography and interpretation of photographs. The quadrats photographed in December 1995 were positioned in the same way as described in Butler \& Connolly 1996. On each piling, 4 subtidal photographs (field $0.3 \times 0.56 \mathrm{~m}$ ) were taken with their top edges at depths of approximately 5, 5.8,6.6 and $7.4 \mathrm{~m}$ below low water level. Beginning at the top of each pile, alternate photographs were taken on the north, south, north, and south side of the pile. Each quadrat was photographed on $35 \mathrm{~mm}$ Ektachrome colour slide film using a Nikonos camera with electronic flash. Although the original design had employed marked, fixed quadrats, the marking was lost early in the study and the positioning of the December 1995 photographs was done approximately by the divers, without measuring devices. Since the area available to them at the estimated location for each photograph was large (the cylindrical steel piles were over $1 \mathrm{~m}$ in diameter), they would not have photographed precisely the same spot as on earlier visits. The positioning of the quadrats had thus become a rule to ensure interspersion of the sampling and a similar sampling of each pile; it was not an attempt to photograph fixed quadrats. On our 17 earlier visits photography was done on $35 \mathrm{~mm}$ film, supplemented with qualitative in situ observations by the divers; on this occasion we also panned each pile (depth 2 to $8 \mathrm{~m}$ ) with a hand-held Hi-8 video camera.

Butler \& Connolly (1996) used a dot-counting method to estimate percentage cover from photographs. For this visit, the slides (for positions 2,3, and 4) were digitized and frames were grabbed from the videotape (for positions 1 and 5, because of a flash failure). The images, as .JPG files, were read into Microsoft Access ${ }^{\circledR}$ where a grid of 234 evenly spaced points was overlaid on them. Macros allowed the operator to record the species covered by each dot directly into an Access database, where further macros calculated percentage cover for each species or group. The data were read from Access into Microsoft Excel ${ }^{\circledast}$, PRIMER $^{\oplus}$ and SYSTAT ${ }^{\mathrm{TM}}$ for statistical analysis. In the work reported by Butler \& Connolly (1996), some specimens were identified by museum specialists, and some from published keys, but many could not be identified to species and, in any case, could not be reliably distinguished in photos or in the field. Therefore, some grouped taxonomic categories were used, and the same has been done with the results reported here.

Analysis of data. This is a nested design in which position along the pier is a fixed factor (5 levels), piles within bents a fixed, nested factor (2 levels), and quadrats within piles are considered as 4 random replicates. The design was a compromise; quadrats were originally intended to be fixed in position at dates prior to December 1995 (13.5 yr), though in practice they were not, as noted above and in Butler \& Connolly 1996. (We originally used fixed quadrats in order to observe succession and to observe the life-cycles of individually recognizable animals.) The quadrat locations could not be found in December 1995, indeed most had been lost by 1989 and some by 1985, so, even prior to December 1995, in many cases photographs were not taken in exactly the same location each time. Thus, although readings taken at different dates are not fully independent, there is a strong element of randomness due to the divers' inability to find the fixed quadrats and in December 1995 there was no intention to do so. Comparison between positions at one time is valid and, given the above, we also feel that a limited number of comparisons can be made between sampling periods.

Temporal changes in the fauna were analysed by (1) using multivariate methods to examine the similarity between positions and how that similarity changed with time, and (2) plotting the abundance of particular taxa against time. Considered at 1 date only (viz., after $13.5 \mathrm{yr}$, in December 1995), the statistical significance of univariate differences between positions and between piles within positions was tested by ANOVA for those few variables that met the assumptions (after log transformation). Significance tests of multivariate differences between positions and between piles were made using ANOSIM (Clarke 1993, Clarke \& Warwick 1994), contributions of different taxa analysed using their SIMPER routine, and patterns of similarity displayed using nonmetric multidimensional scaling (MDS). For multivariate analyses, raw counts were transformed using $x^{0.25}$ to emphasise the distribution of less common species in the analysis, and the Bray-Curtis similarity coefficient was used throughout. Counts and percentage cover were used together in these analyses. The difference in scale could, theoretically, have had a large influence on plots. Multivariate analyses were also done on standardised data, but the patterns were qualitatively the same, and so these results are not shown. Further details of design and analysis are discussed in Butler \& Connolly (1996)

\section{RESULTS}

\section{Taxa recorded}

No new species were noticed on this visit; we were particularly alert for the polychaete Sabella cf. spallan- 
Table 1. Categories of organisms recognized in scoring subtidal photographs from Port Bonython pier, 14 December 1995 . The abundance of those marked " was used in multivariate analyses and of those marked $\cdots$ also used in univariate tests for differences between positions and changes through time. $\mathrm{N}=$ number per quadrat counted; \% $\mathrm{C}=$ percent cover estimated

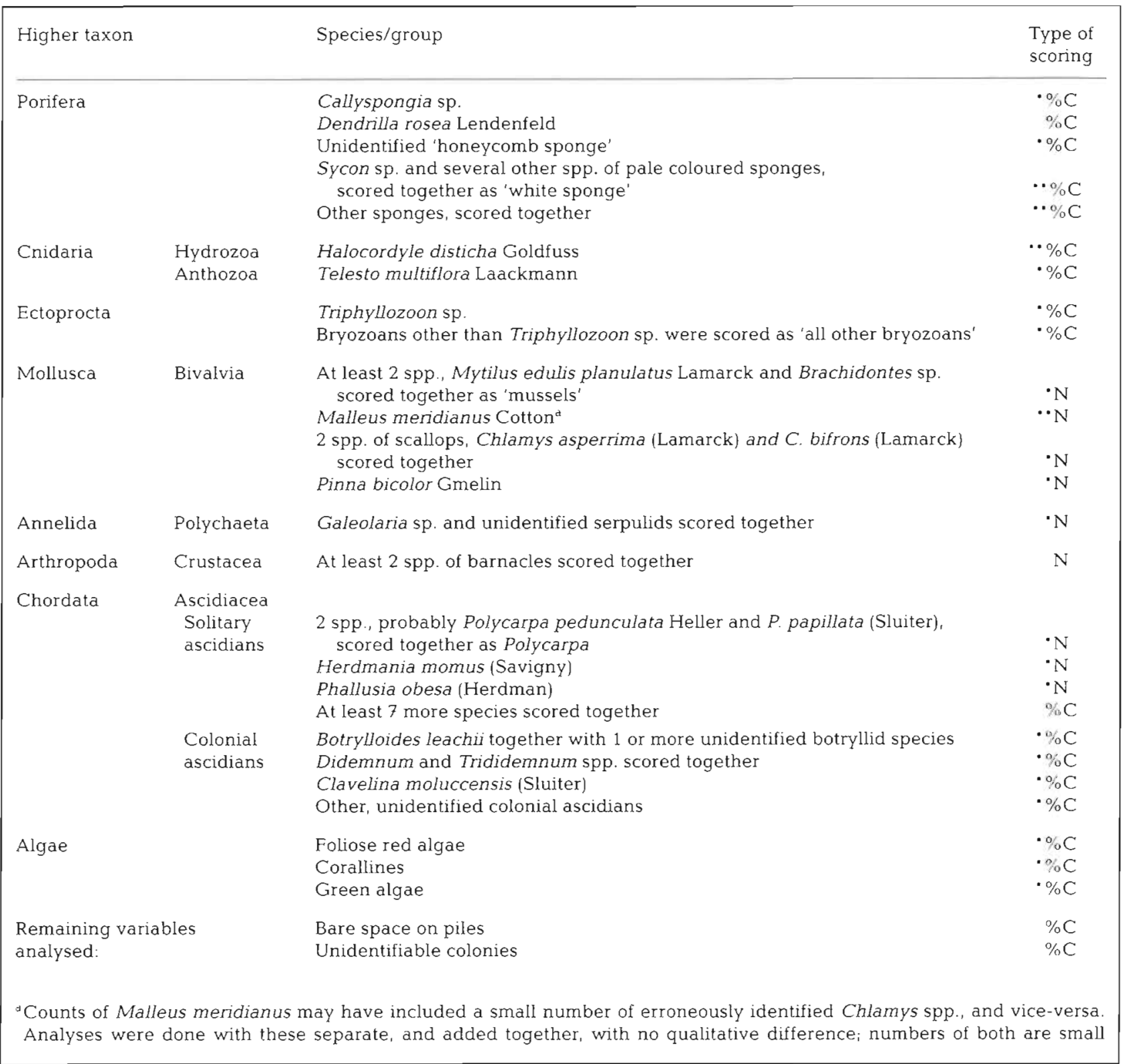

zanii, which had been introduced to other sites in South Australia, so this can be taken as a negative record for that species. Because of the taxonomic limitations, some grouped categories are used, as in Butler \& Connolly (1996). Of at least 70 species or groups that could be distinguished in the slides throughout the whole study, some were too unreliably distinguished by the scorers for statistical analysis. Twenty-three species or groups were included in multivariate analyses. Of these, 4 were sufficiently abundant for univariate analysis. Table 1 indicates the species/groups distinguished for analysis.

\section{Differences between positions after ca 13.5 yr as a multivariate process}

The MDS for ca $13.5 \mathrm{yr}$ after immersion is shown in Fig. 1. The differences between positions are significant (nested ANOSIM, piles $p=0.081$, positions $p=$ 0.033 ). In pairwise comparisons, using all 8 quadrats as replicates for each position, position 1 is different from all others, as is position 5, but positions 2, 3 and 4 do not differ significantly. The SIMPER analysis of the contributions of different groups to the similarity 


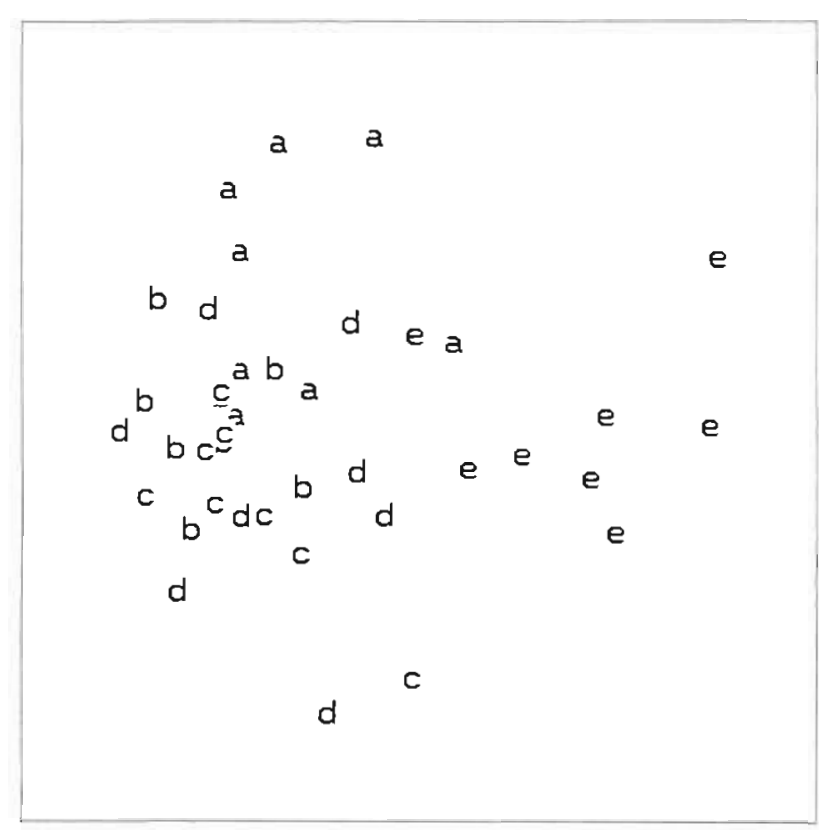

Fig. 1. Nonmetric multidimensional scaling plot in 2 dimensions of the similarity (Bray-Curtis) between positions ( $n=8$ quadrats within a position) after 13.5 yr. Positions are represented by: $a=1, b=2, c=3, d=4, e=5$. Stress $=0.17$

shows that there is no simple or global explanation for differences between positions but Halocordyle disticha, white sponge, other sponges, and red algae commonly contributed a substantial percentage to pairwise differences between positions, whilst Malleus meridianus and green algae were sometimes important and Clavelina moluccensis contributed strongly to differences between position 5 and each other position. Telesto multiflora and Polycarpa spp., which had been major contributors after $6.5 \mathrm{yr}$, were not important after 13.5 yr.

\section{Dynamics of the assemblage as a multivariate process}

Fig. 2 shows the MDS for 6.5 and 13.5 yr. There is complete separation of the quadrats for the 2 dates, and those for $6.5 \mathrm{yr}$ are more scattered (less similar to one another) than those for $13.5 \mathrm{yr}$. The ANOSIM shows that both date and position effects are highly significant $(\mathrm{p}<0.001)$ and that positions 1 and 5 are significantly different from the rest, whilst positions 2 , 3 and 4 do not differ significantly. Neither the ANOSIM results (separately at 6.5 and 13.5 yr) nor inspection of Fig. 2 indicates a strong interaction between the effects of date and position.

To obtain a picture of trends over the whole study period, we compared the results after $2.5,6.5$ and $13.5 \mathrm{yr}$. These dates were well spaced and each was in

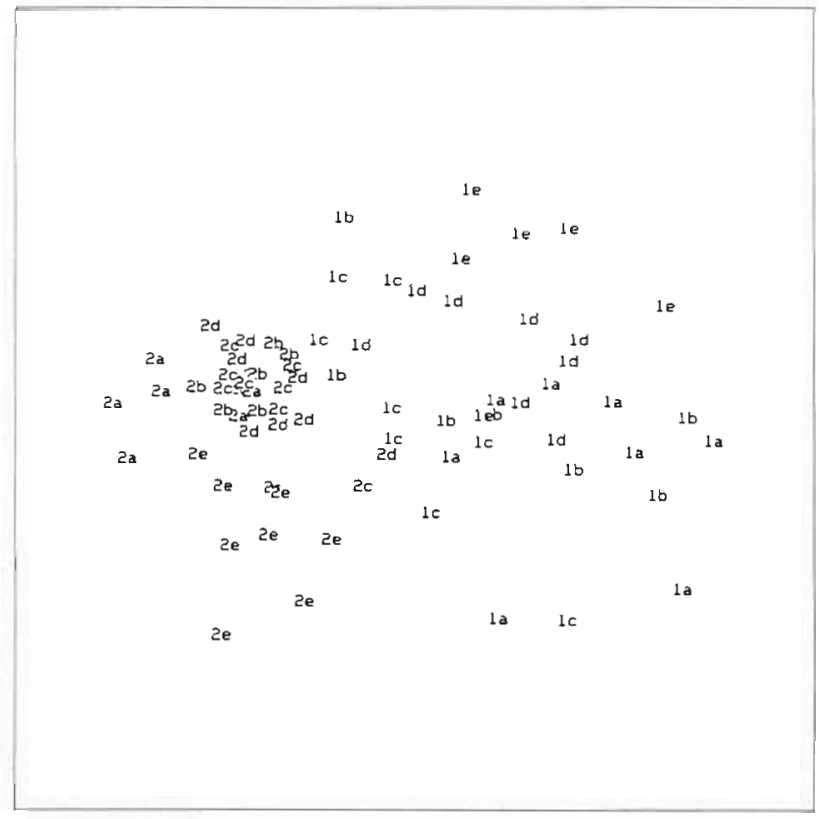

Fig. 2. Nonmetric multidimensional scaling plot in 2 dimensions of the similarity (Bray-Curtis) between quadrats $(8$ quadrats for each position) at 6.5 and $13.5 \mathrm{yr}$. Dates are represented as $1=6.5 \mathrm{yr}, 2=13.5 \mathrm{yr}$ and positions by $\mathrm{a}=1, b=2$, $\mathrm{c}=3, \mathrm{~d}=4, \mathrm{e}=5$. Stress $=0.15$

the warmer months of the year when the data were not distorted by winter-blooming colonial ascidians. Analyses were done at 2 levels of resolution: individual quadrats (there are 40 of these for each date), and means over the 8 quadrats for each position (hence, 5 per date), with almost identical conclusions. (Butler \& Connolly 1996 discussed the reasons for treating quadrats as replicates within a position.) Fig. 3 shows the MDS plot for averages over the 8 quadrats within each position after $2.5,6.5$ and 13.5 yr. There are differences between positions at each date, and clear separation between dates; the composition of the biota on the whole pier at $13.5 \mathrm{yr}$ is more dissimilar from the earlier dates than positions are from one another. The ANOSIM shows that both date and position effects are significant $(p<0.001)$ with all dates different from each other $(p<0.001)$ and all pairs of positions significantly different (at $p<0.002$ or lower) except positions 2 and $3(p=0.107)$. There is only a weak indication of interaction between effects of position and date. The pattern of differences amongst positions was the same at $6.5 \mathrm{yr}$ as at $13.5 \mathrm{yr}$ (see above; positions 1 and 5 differ from the rest), whilst at $2.5 \mathrm{yr}$ it is positions 1 and 4 that differ from the rest (Butler \& Connolly 1996).

The stress values for the MDS plots are acceptable (Clarke 1993) but not low; there is much variation within positions and not very clear differences between positions. However, the ANOSIM results (above) do indicate that the differences in the MDS plots are significant. 


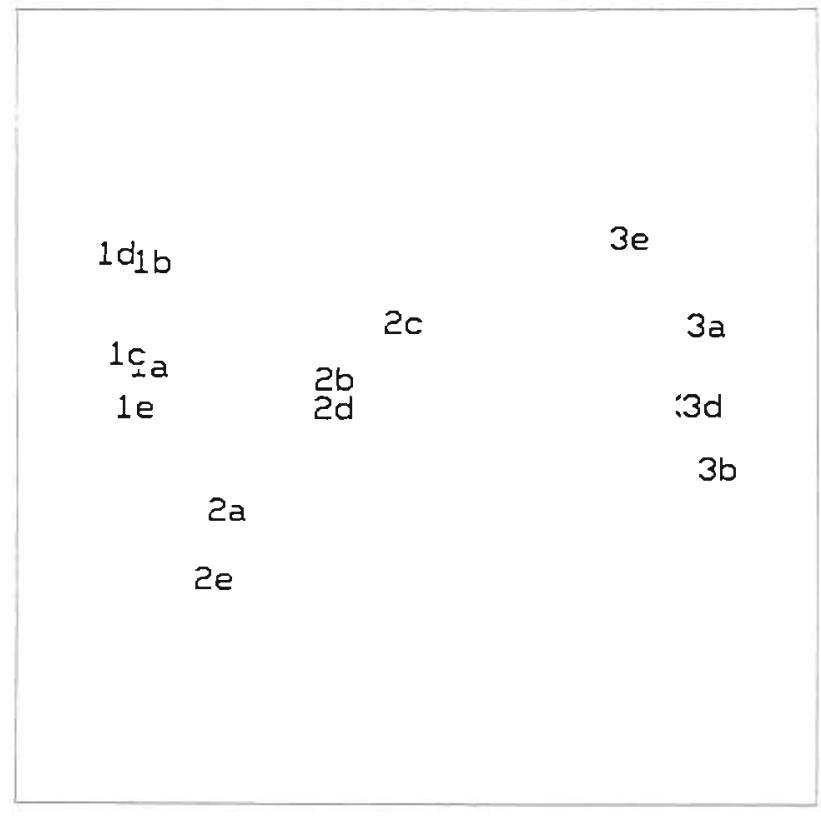

Fig. 3. Nonmetric multidimensional scaling plot in 2 dimensions of the similarity (Bray-Curtis) between positions (8 quadrats within a position averaged) at 3 dates. Dates are represented as $1=2.5 \mathrm{yr}, 2=6.5 \mathrm{yr}, 3=13.5 \mathrm{yr}$ and positions by $a=1, b=2, c=3, d=4, e=5$. Stress $=0.14$

\section{Dynamics of the assemblage at population level}

The first photographic data analysed were those for our eighth visit to the site, July 1984, 2 yr after construction. Sheet-, mound- and tree-form modular organisms, especially sponges and Telesto multiflora Laackmann, were abundant by this time along with unitary organisms, especially bivalves and ascidians. Four yr later this was still the case, although certain unitary organisms (Electroma georgiana, Ostrea angasi, Anomia trigonopsis) had virtually disappeared and others (Phallusia obesa, Polycarpa spp., Herdmania momus) appeared to be declining (Butler \& Connolly 1996). Modular forms had become much more dominant after ca $13.5 \mathrm{yr}$. To illustrate this, the data were grouped into 3 broad modular categories as follows. Encrusting and mound-forming modular animals (sponges, colonial ascidians, bryozoans) occupied $20 \%$ at $6.5 \mathrm{yr}$ and $54 \%$ at $13.5 \mathrm{yr}$. The cover of branching modular animals ( $T$. multiflora, hydroids) was $26 \%$ at $6.5 \mathrm{yr}$, and $18 \%$ at $13.5 \mathrm{yr}$. Red algae increased from $5 \%$ at 6.5 yr to $25 \%$ at $13.5 \mathrm{yr}$.

From July 1984, the trajectory of the biota can be described simply by plotting the means, for each of the 5 positions, of taxon abundances against time since the construction of the loading platform. This has been done for 12 species/groups and for bare space. As examples, the plots for 3 animal groups and for bare space are shown in Fig. 4.
The behaviour of these 13 variables can be described under 4 categories:

(1) Taxa that have dropped to very low abundance by 13.5 yr (some had been rising, some steady at 6.5 yr) An example is the hammer oyster Malleus meridianus (Fig. 4a); others include the scallops Chlamys spp., didemnid and botryllid ascidians, the solitary ascidians Phallusia obesa, Polycarpa spp. and Herdmania momus, and the soft coral Telesto multiflora. Most are unitary organisms. For most of these species, numbers were always low at certain positions (not the same positions for different species, however) and initially high at others; numbers dropped through time at the positions where they had initially been high. For some, however, ( $M$. meridianus, $T$. multiflora) numbers had been high though variable for most of the initial $6.5 \mathrm{yr}$.

(2) Species whose numbers appeared to be generally rising to $6.5 \mathrm{yr}$, and were of about the same abundance at $13.5 \mathrm{yr}$. These were modular organisms, namely the category white sponge (Fig. 4b) and the hydroids scored as Halocordyle disticha.

(3) Groups that had increased strongly between 6.5 and $13.5 \mathrm{yr}$. There were 2 such variables. Firstly, the group called other sponges (some of these can be identified to genus, notably Callyspongia, but the scorer was instructed to score them all, conservatively, as 1 group) had occupied a modest, variable but increasing amount of space up to $6.5 \mathrm{yr}$. This had risen to about $30 \%$ cover at $13.5 \mathrm{yr}$ (Fig. 4c), at which date sponges (white sponge and other sponges pooled) occupied 40 to $50 \%$ of space, comparable with other South Australian piers (Kay \& Butler 1983, Butler 1986). Secondly, red algae increased from $5 \%$ at 6.5 yr to approximately $25 \%$ cover at $13.5 \mathrm{yr}$.

(4) Variable but always low, and not recorded (or seen by divers in the field, despite specific searching) at $13.5 \mathrm{yr}$. This category contained only 1 variable, namely bare space (Fig. 4 d).

\section{Differences at population level between positions after ca $13.5 \mathrm{yr}$}

A small subset of the variables approximated the properties required for parametric analysis, and for 4 of them the pattern of difference between positions was examined using ANOVA on log-transformed data at $13.5 \mathrm{yr}$. Results of the ANOVAs (piles nested within positions; quadrats as replicates within piles) are summarised in Table 2. For no species is there a significant position effect, and only for white sponge is there a significant effect of pile within position. Positions seemed to be quite similar with respect to these taxa, even though they (along with red and green algae) were the main contributors to the multivariate dissimilarities. 

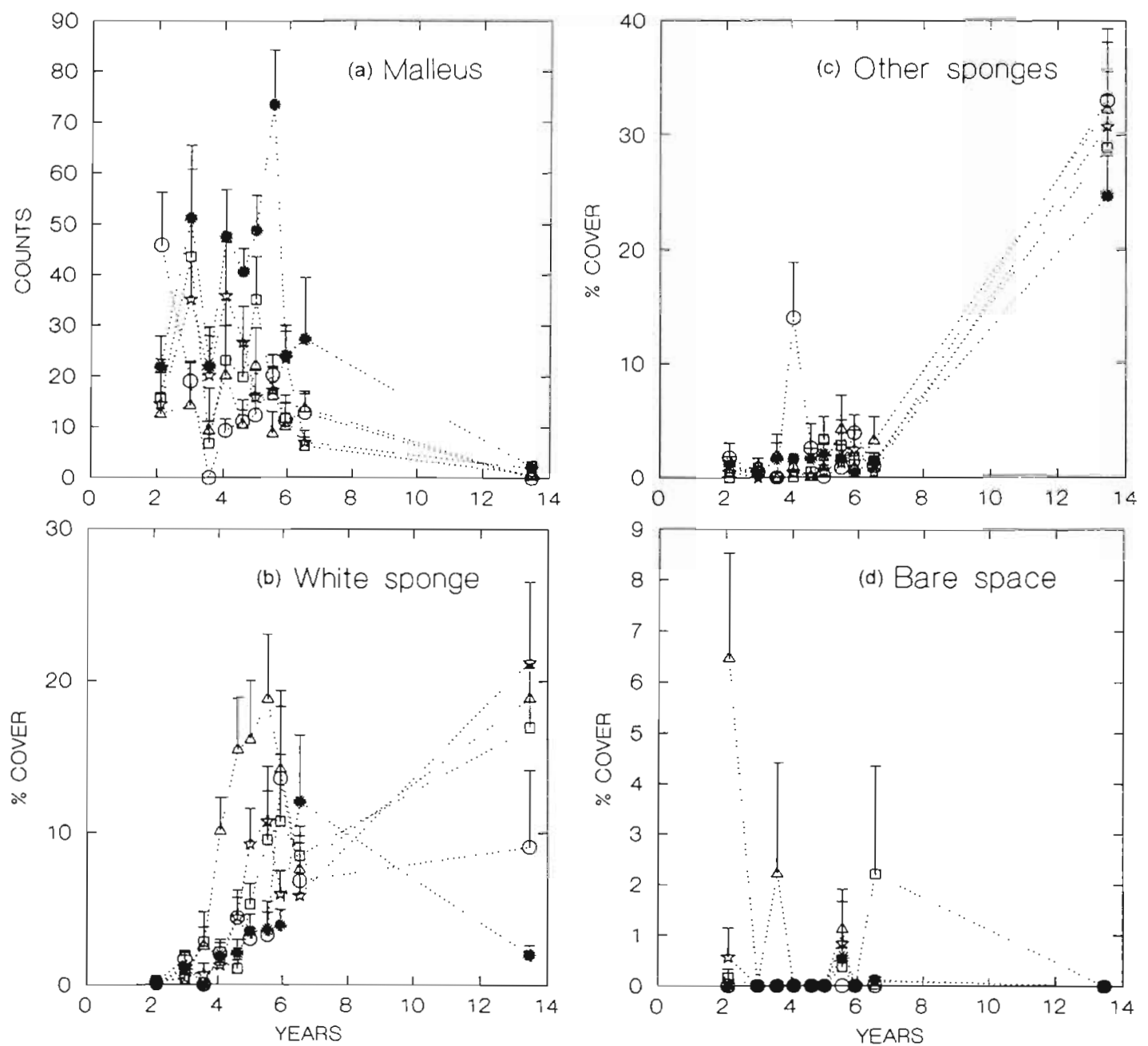

Fig. 4. Plots of single variables against time in years since the construction of the loading platform. These graphs extend those presented in Butler \& Connolly (1996). Bars are SE. Positions are represented by $O=1, \triangle=2, \square=3$, 故 $=4$, $=5$. (a) Malleus meridianus counts; (b) percent cover of white sponge; (c) percent cover of other sponges; (d) percent of bare space

\section{DISCUSSION}

The assemblages on the piles changed as greatly over the second half of the study period as over the first. Because we do not have observations between 6.5 and $13.5 \mathrm{yr}$, there is little evidence as to whether change is still continuing at the same rate as earlier, and no way of knowing whether there was a smooth trajectory between 6.5 and 13.5 yr, or wide fluctuations of the kind observed between 2 and 6.5 yr (see Fig. 4).

It might be considered of interest whether the 'variance' of the data changes between one date and the next. Indeed, it seems to do so. This is indicated by the spacing of points in Fig. 2; to confirm it, the Index of

Table 2. Nested analysis of variance on 4 variables, approximately $13.5 \mathrm{yr}$ after completion of the loading platform. $\mathrm{N}=$ the variable was a count; $\% \mathrm{C}=$ variable was percentage cover. The factor Pile is nested within main factor Position. ns = not significant at $5 \%$ level. $\cdots p<0.01$

\begin{tabular}{|c|c|c|c|c|c|c|c|}
\hline \multirow[t]{2}{*}{ Variable } & \multicolumn{3}{|c|}{ Position (df 4,5$)$} & \multicolumn{3}{|c|}{ Pile (df 5,30 ) } & \multirow{2}{*}{$\begin{array}{c}\text { Error } \\
\text { MS }\end{array}$} \\
\hline & MS & $F$ & $\mathrm{p}$ & MS & $F$ & $\mathrm{p}$ & \\
\hline Malleus meridianus ( $\mathrm{N}$ ) & 0.20 & 1.90 & $>0.5 \mathrm{~ns}$ & 0.10 & 1.18 & 0.345 ns & 0.09 \\
\hline Halocordyle disticha $(\% \mathrm{C})$ & 1.23 & 4.08 & $>0.1 \mathrm{~ns}$ & 0.30 & 1.21 & $0.331 \mathrm{~ns}$ & 0.25 \\
\hline White sponge $(\% \mathrm{C})$ & 1.27 & 2.27 & $>0.5 \mathrm{~ns}$ & 0.56 & 4.41 & $0.004 \cdots$ & 0.13 \\
\hline Other sponges $(\% \mathrm{C})$ & 0.01 & 0.17 & $>0.5 \mathrm{~ns}$ & 0.06 & 0.716 & $0.616 \mathrm{~ns}$ & 0.08 \\
\hline
\end{tabular}


Multivariate Dispersion calculated by PRIMER is 1.19 for $6.5 \mathrm{yr}$ and 0.81 for $13.5 \mathrm{yr}$. However, this is an index of spatial variation between positions at one time. In discussing 'stability' of the assemblage, we are interested in the magnitude of its changes through time. The only indicator we have of this is the multivariate distance between the assemblages at different dates, not their spatial variation at a given date.

Our working hypotheses in this project were that the fauna on different groups of piles (positions) would converge to some common composition dominated by modular organisms and that this common assemblage would represent a 'stable' condition (showing little change with time; cf. the test for 'narrow stochastic boundedness' used by Kay \& Butler 1983 and Keough \& Butler 1983). If the fauna on different groups of piles did not reach a common composition, then we would ask which species contributed to similarities and differences between groups of piles, and we would seek indications of the possible effects of environmental variables.

From experience at other piers in South Australia (Butler \& Chesson 1990 and references cited therein), we had expected modular organisms to become progressively more dominant, overgrowing and displacing the unitary forms, which would eventually persist in the system at a low relative abundance, as 'fugitive species'. However, Butler \& Connolly (1996) concluded that this had not occurred to the extent expected. After a further $7 \mathrm{yr}$, it has now done so; unitary animals, especially Malleus meridianus, Phallusia obesa and Polycarpa spp., which were still very abundant after $6.5 \mathrm{yr}$, have either disappeared or dropped to modest abundances, similar to those observed at our other study sites. The percentage cover of encrusting and mound-form modular organisms is now very high (54\%); foliose modular forms are also abundant (animals $18 \%$; red algae an additional $25 \%$ ).

In noting that the fauna of Port Bonython now conforms more to our prediction (dominance by modular organisms) we do not mean to suggest that the fauna has the same composition as that at the other piers we have studied (especially at Edithburgh and Rapid Bay in Gulf St Vincent). Local physical or nutritional conditions are clearly important in determining the particular species that are abundant at a site, in addition to any more general mechanism favouring modular over solitary forms. Hydroids, in particular, have remained more abundant at Port Bonython than at Edithburgh and Rapid Bay, whilst the faunas of those 2 piers remain different from one another (Kay \& Butler 1983, Butler 1986).

It is difficult to compare the physical and nutritional conditions at different sites and this is an issue for future research. The only data we have concern rates of 'disturbance', but even this is difficult to interpret because our measures integrate (and therefore confound) the effects of wave action, substratum type and the characteristics of the biota. Bare space, for example, is lower at Port Bonython than at the undoubtedly more sheltered Edithburgh pier; it was less than $1 \%$ on most positions up to $6.5 \mathrm{yr}$, and none of it was recorded at $13.5 \mathrm{yr}$

The patterns of change through time differ markedly for different taxa. The pier had been rapidly colonised and then the fauna continued to change, as illustrated by the 'roughiy parallel' movement of positions across the MDS plot in Fig. 2 of Butler \& Connolly (1996). By 6.5 yr there had still been a considerable abundance of solitary organisms on the piles as well as the extensive development of modular animals and red algae. Now, at $13.5 \mathrm{yr}$, many of those solitary organisms have disappeared and the piles are dominated by modular organisms, and this is reflected in the major separation of the data for $13.5 \mathrm{yr}$ from those for 2.5 and $6.5 \mathrm{yr}$ in Fig. 3. The univariate changes over time in particular taxa or groups are clear (Fig. 4); hence, it is easy to see why the assemblage changes over time (over and above position differences). However, the univariate differences among positions vary with species (Fig. 4) and in any case are not significant (Table 2); yet, at the assemblage level, position differences are consistent between 6.5 and $13.5 \mathrm{yr}$. This illustrates how a test on the overall composition of the assemblage can detect differences that are not clear when examining individual components (taxa).

Despite their very similar trajectories in the first few years of the study, the assemblages on the 5 positions spaced along the pier had remained significantly different through the first $6.5 \mathrm{yr}$. Positions were significantly different at each date but not in consistent ways through time. After the first $6.5 \mathrm{yr}$, the following qualitative model was plausible: the biota of the pier is highly variable in space and time ('noisy') on small scales (quadrats, positions) but is, nevertheless, at the 'pier' scale approaching the 'narrowly stochastically bounded' (NSB) situation characteristic of several sites in Gulf St Vincent (Kay \& Butler 1983). This is Model $1 \mathrm{~A}$ of the 'Introduction' Our prediction from this model was that at a later date positions would differ from one another and each position would differ from its condition in 1989 but that the pier as a whole would not be strongly different from 1989; under that prediction, a 2-way ANOSIM (factors; date and position) should find significant position effects overall, little overall date effect but a significant interaction between date and position, evidenced by clear position effects at each date but with a different pattern at each date. We did not obtain that result; there was a strong date effect. 
Model 1B states that Model 1A is true, except that the pier had not yet converged to the NSB condition by $6.5 \mathrm{yr}$. It predicts significant position effects, a date effect and an interaction. We found such a result except that the interaction (which could not be formally tested but only inferred from differences in the pattern of the position effect) was negligible.

An alternative model (Model 2) was that the position differences are not merely 'noise' but reflect environmental differences between positions, such as differences in wave attack or current speed. Again, there are 2 versions, one postulating that the system has converged to a NSB condition by $6.5 \mathrm{yr}$ and the other that it has not. Model $2 \mathrm{~A}$ would predict that at 13.5 yr we would find not only that the composition of the assemblage over the whole pier is similar to that at 6.5 yr but also that each position is similar to its composition then, and that positions differ in the same ways; a 2-way ANOSIM (date-position) should find a significant position effect but no significant date effect nor implied interaction, from examining the separate 1 -way ANOSIM tests. We did not obtain that result. Model 2B predicts that the pier as a whole would have continued to change (hence there would be a significant date effect), the positions would continue to differ (a significant position effect) and it is not possible to say whether there should be an implied interaction

In fact, there is a position effect at each date, the pier overall has changed (i.e. there is a date effect; every position differs from its condition 7 yr earlier), but as far as can be judged from the ANOSIM tests, the relationships between the positions may not have changed greatly (i.e. any implied interaction is weak).

The observed result most closely fits the predictions of Model 2B. Evidently, the composition of the fauna on the pier had not 'stabilised' (become NSB) by 6.5 yr. It was still shifting in the direction of dominance by modular organisms. Although the composition of the pier now looks more like that of the 'stable' assemblages at other sites, we still cannot apply a test for 'stability' defined as NSB because there are no data from Years 7 to 13. (Keough \& Butler [1983] showed that at least 6 sampling dates were needed to apply their test for NSB. Thus, we could not apply the test around $6.5 \mathrm{yr}$ because there were not enough sampling dates during the period when it appeared that the rate of change may have decreased; we could not apply it at 13 yr for the same reason.)

The pattern of differences amongst positions was the same at $13.5 \mathrm{yr}$ as at $6.5 \mathrm{yr}$. At both dates, positions 1 and 5 were distinct; positions 2, 3 and 4 were similar to one another (Fig. 1). This was so at 6.5 yr and may be attributable to environmental characteristics unique to the loading platform, but it has not been so throughout the study (e.g. at $2.5 \mathrm{yr}$, positions 2,3 and 5 did not differ significantly but position 4 was distinctive). We lack sufficient data to examine this critically, but can offer the following comments. An inspection of the SIMPER results, and also of the slides themselves and the divers' impressions in the field, indicates that there is no one group of organisms distinguishing positions from one another at 13.5 yr excepting that Clavelina moluccensis is very abundant only at the loading platform. C. moluccensis was not an important disciminator between position 5 and other positions at $6.5 \mathrm{yr}$. It has limited dispersal (Davis \& Butler 1989) and was a late colonist of this pier. As discussed by Butler \& Connolly (1996), there are strong tidal currents forming a gyre centred on about position 3 , with greatest current speeds at positions 1 and 5; position 5 (the loading platform) is more shaded and deeper than positions 1 to 4 . It is also true that positions 1 and 5 were constructed earliest, but since they did not show consistent differences from the other positions at earlier dates it is implausible that their slightly greater age accounts for the differences observed at $13.5 \mathrm{yr}$.

It might be argued that the major human-induced differences between positions along the pier now result from events at the loading platform. If spills occur (there was a spill from the tanker 'Era' in August 1992, Butler 1993), they and any remedial treatments used are likely to affect the loading platform. Release of treated ballast water between positions 2 and 3 is now rare. Few ships now carry ballast water in product tanks; they have separate ballast water tanks, and it is common for ships to discharge untreated ballast water whilst berthed at the loading platform. However, we found no differences between position 5 and the other positions that could be attributed to oil spills or the release of ballast water.

In conclusion, we reiterate the common plea for long-term studies. We do not wish to make any case for hypothesis-free data-gathering, but argue for a recognition that some biological processes move too slowly to be understood after a brief investigation. In the present case, our conclusions after a 6 to 7 yr study (already exceptionally long by current funding standards) were shown to be erroneous when re-examined after $13.5 \mathrm{yr}$, and still some aspects of the data cannot be interpreted confidently because there are insufficient samples through time.

Acknowledgements. For assistance in the field we thank Emma Cronin, Ian Magraith, Andrew Melville and Craig Styan. Data were extracted from the images by David Miller using a system developed by Anthony Cheshire and David Miller. Thanks to Santos Ltd for permission to publish, and to the Santos staff at Port Bonython and in Adelaide for their support. We are grateful to Andy Davis, Tim Glasby and Dave Schiel for their helpful comments on the manuscript 


\section{LITERATURE CITED}

Anger K (1978) Development of a subtidal epifaunal community at the island of Helgoland. Helgol Wiss Meeresunters $31: 457-470$

Buss LW (1979) Habitat. selection, directional growth and spatial refuges: why colonial animals have more hiding places. In: Larwood GP, Rosen BR (eds) Biology and systematics of colonial organisms. Academic Press, New York, p 459-497

Buss LW, Jackson JBC (1979) Competitive networks: nontransitive competitive relationships in cryptic coral reef communities. Am Nat 113:223-234

Butler AJ (1986) Recruitment of sessile invertebrates at 5 sites in Gulf St Vincent, South Australia. J Exp Mar Biol Ecol 97 : $1.3-36$

Butler AJ (1991) Effect of patch size on communities of sessile invertebrates in Gulf St Vincent, South Australia. J Exp Mar Biol Ecol 153:255-280

Butler AJ (1993) Monitoring the effects of the Era oil spill. Report to the Minister of Environment and Land Management. Environmental Protection Council, Adelaide

Butler AJ, Chesson PL (1990) Ecology of sessile animals on hard substrata: the need to measure variation. Aust J Ecol 15:521-531

Butler AJ, Connolly RM (1996) Development and long term dynamics of a fouling assemblage of sessile marine invertebrates. Biofouling 9:187-209

Butler AJ, Keough MJ (1990) A comment on short supplylines. Trends Ecol Evol 5:97

Chernoff $\mathrm{H}$ (1987) Factors affecting mortality of the scallop Chlamys asperrima (Lamarck) and its epizoic sponges in South Australian waters. J Exp Mar Biol Ecol 109:155-171

Christie H (1983) Natural fluctuations in a rocky subtidal community in the Oslo Fjord (Norway). In: Cabioch L, Glémarec M, Samain JF (eds) Proc 17th Eur Mar Biol Symp. Oceanol Acta Vol Spec, p 69-73

Clarke KR (1993) Non-parametric multivariate analyses of changes in community structure. Aust J Ecol 18:117-143

Clarke KR, Warwick RM (1994) Change in marine communities: an approach to statistical analysis and interpretation. Natural Environment Research Council, Plymouth

Connell JH, Keough MJ (1985) Disturbance and patch dynamics of subtidal marine animals on hard substrata. In: Pickett STA, White PS (eds) The ecology of natural disturbance and patch dynamics. Academic Press, New York, p $121-151$

Coyer JA, Ambrose RF, Engle JM, Carroll JC (1993) Interaction between corals and algae on a temperate zone rocky reef: mediation by sea urchins. J Exp Mar Biol Ecol 167: $21-37$

Davis AR (1987) Variation in recruitment of the subtidal colonial ascidian Podoclavella cylindrica (Quoy \& Gaimard): the role of substratum choice and early survival. J Exp Mar Biol. Ecol 106:57-71.

Davis AR (1988) Effects of variation in initial settlement on distribution and abundance of Podoclavella moluccensis Sluiter. J Exp Mar Biol Ecol 117:157-167

Davis AR, Butler AJ (1989) Direct observations of larval dispersal in the colonial ascidian Podoclavella moluccensis Sluiter: evidence for closed populations. J Exp Mar Biol Ecol 127:189-203

Jackson JBC (1977) Competition on marine hard substrata: the adaptive significance of solitary and colonial strategies. Am Nat 111:743-767

Jackson JBC (1979) Morphological strategies of sessile animals. In: Larwood GP, Rosen BR (eds) Biology and system. atics of colonial organisms. Academic Press, New York, p 499-555

Karlson RH (1985) Competitive overgrowth interactions among sessile colonial invertebrates: a comparison of stochastic and phenotypic variation. Ecol Model 27 $299-312$

Karlson RH, Buss LW (1984) Competition, disturbance and local diversity patterns of substratum-bound clonal organisms: a simulation. Ecol Model 23:243-255

Karlson RH, Jackson JBC (1981) Competitive networks and community structure: a simulation study. Ecology 62 $670-678$

Kay AM, Butler AJ (1983) 'Stability' of the fouling communities on the pilings of two piers in South Australia. Oecologia 56:58-66

Kay AM, Keough MJ (1981) Occupation of patches in the epifaunal communities on pier pilings and the bivalve Pinna bicolor at Edithburgh, South Australia. Oecologia 48 $123-130$

Keough MJ (1984a) Effects of patch size on the abundance of sessile marine invertebrates. Ecology 65:423-437

Keough MJ (1984b) Dynamics of the epifauna of the bivalve Pinna bicolor: interactions among recruitment, predation and competition. Ecology 65:677-688

Keough MJ, Butler AJ (1983) Temporal changes in species number in an assemblage of sessile marine invertebrates. J Biogeogr 10:317-330

Keough MJ, Chernoff H (1987) Dispersal and population variation in the bryozoan Bugula neritina. Ecology 68:199-210

McKinney FK (1992) Competitive interactions between related clades: evolutionary implications of overgrowth interactions between encrusting cyclostome and cheilostome bryozoans. Mar Biol 114:645-652

Okamura $B(1988)$ The influence of neighbours on the feeding of an epifaunal bryozoan. I Exp Mar Biol Ecol 120: $105-123$

Olson RR (1985) The consequences of short-distance larval dispersal in a sessile marine invertebrate. Ecology 66: $30-39$

Osman RW (1977) Establishment and development of a marine epifaunal community. Ecol Monogr 47:37-64

Osman RW, Whitlatch RB, Zajac RN (1989) Effects of resident species on recruitment into a community: larval settlement versus post-settlement mortality in the oyster Crassostrea virginica. Mar Ecol Prog Ser 54:61-73

Osman RW, Whitlatch RB, Malatesta RJ (1992) Potential role of micro-predators in determining recruitment into a marine community. Mar Ecol Prog Ser 83:35-43

Russ GR (1980) Effects of predation by fishes, competition, and structural complexity of the substratum on the establishment of a marine epifaunal community. J Exp Mar Biol Ecol 42:55-70

Schmidt GH, Warner GF (1984) Effects of caging on the development of a sessile epifaunal community. Mar Ecol Prog Ser 15:251-263

Sebens KP (1985) Community ecology of vertical rock walls in the Gulf of Maine, USA: small-scale processes and alternative community states. In: Moore PG, Seed R (eds) The ecology of rocky coasts. Hodder \& Stoughton, London, p 346-371

Sutherland JP (1974) Multiple stable points in natural communities. Am Nat 108:859-872

Sutherland JP (1981) The fouling community at Beaufort, North Carolina: a study in stability. Am Nat 118:499-519

Svane I, Lundalv T (1981) Reproductive patterns and population dynamics of Ascidia mentula O.F. Müller on the Swedish west coast. J Exp Mar Biol Ecol 50:163-182 